port. J Pediatr 101:700

40. Whitmer JT, Idell-Wenger JA, Rovetto MJ, Neely JR 1978 Control of fatty acid metabolism in ischemic and hypoxic hearts. J Biol Chem 253:4305
41. Wood JM, Bush B, Pitts BJR, Schwartz A 1977 Inhibition of bovine heart $\mathrm{Na}^{+}$ $\mathrm{K}^{+} \mathrm{ATPase}$ by palmityl carnitine and palmityl CoA. Biochem Biophys Res Commun 74:677

\title{
Respiratory Syncytial Virus-Specific IgE Responses following Infection: Evidence for a Predominantly Mucosal Response
}

\author{
ROBERT C. WELLIVER, MARTHA SUN, DEBORAH RINALDO, AND PEARAY L. OGRA \\ Department of Pediatrics and Microbiology, State University of New York at Buffalo, and Division of Infectious \\ Diseases, Children's Hospital, Buffalo, New York 14222
}

\begin{abstract}
In order to determine whether IgE production occurs predominantly at mucosal or systemic sites, we studied the production of respiratory syncytial virus (RSV)specific antibody in serum and nasopharyngeal secretions (NPS) from 41 patients with RSV infection using an enzyme-linked immunosorbent assay. RSV-IgE was found in higher titer in samples of NPS than in simultaneously obtained serum specimens at all phases of illness. Despite the excess dilution incurred in the collection process, RSVIgE was frequently detected in NPS specimens while it was undetectable in serum. In 20 selected subjects, ratios of RSV antibody in NPS:serum were 2.00 for RSV-IgE, 2.42 for RSV-IgA, and 0.01 for RSV-IgG. Also the geometric mean value of ratios of RSV-IgE:RSV-IgG was 1.74 in NPS and 0.05 in serum, while the geometric mean value of ratios of RSV-IgA:RSV-IgG were 1.85 in NPS and 0.09 in serum. These data suggest that IgE production occurs predominantly at mucosal surfaces. (Pediatr Res 19: 420424, 1985)
\end{abstract}

\section{Abbreviations}

RSV, respiratory syncytial virus

NPS, nasopharyngeal secretions

ELISA, enzyme-linked immunosorbent assay

URI, upper respiratory tract infection

GMT, geometric mean titer

Although the importance of $\operatorname{IgE}$ as a mediator of hypersensitivity diseases has been well established, the site of production of this immunoglobulin isotype remains controversial. Investigations of IgE production in the respiratory tract have demonstrated increased ratios of total IgE to albumin in respiratory secre-

Received September 10, 1984; accepted December 21, 1984

Reprint address Dr. Robert C. Welliver, Division of Infectious Diseases, Children's Hospital, 219 Bryant Street, Buffalo, NY 14222.

Supported by grants from the National Heart, Lung and Blood Institute (HL21829-05), the National Institute of Allergy and Infectious Diseases (AI-15939-01), and the National Institute of Child Health and Human Development (HD-1594302). tions in comparison to serum (1) as well as indirect evidence that grass pollen-specific IgE antibody in nasal secretions is produced locally (2). The study of IgE responses to an infectious agent would allow for an evaluation of the kinetics of IgE production at both systemic and mucosal sites following a single exposure to the antigen. Any potential modulating effects on antibody responses from repeated exposure to an antigen such as grass pollen would therefore be avoided.

$\mathrm{RSV}$ is a common cause of respiratory illness in young infants, and severe forms of illness appear to be mediated, at least in part, by the production of RSV-specific IgE antibody. We undertook the current study of the antibody response in serum and NPS to RSV infection in order to determine whether IgE antibody responses to an infectious agent occur primarily at mucosal or systemic immunocompetent tissue sites. The data suggest that, while RSV infection stimulates a strong antibody response at both sites, IgE antibody to the virus is formed in much greater quantities in the respiratory tract.

\section{MATERIALS AND METHODS}

Patient population and sample collection. The study population consisted of 41 infants less than 1 yr of age either hospitalized due to RSV infection or followed as part of an ongoing study of respiratory illnesses in childhood. At the time of recruitment into the study, the objectives and risks of the study were explained and a signed statement of informed consent was obtained. Patients were classified as having either URI alone, pneumonia, or bronchiolitis on the basis of clinical and radiographic criteria described in previous publications from this laboratory (3). According to these criteria, nine patients had URI alone, five had pneumonia without wheezing, and 27 had bronchiolitis. All patients had been in good health until the time of RSV infection.

Samples of NPS were obtained at the time of recruitment by passing an 8 French polyethylene catheter into the nasopharynx via the nares and applying gentle suction followed by rinsing into mucus traps. Duplicate samples of NPS were obtained both for documentation of RSV infection and for determination of RSV antibody titer. A sample of serum was also obtained. Patients were requested to return in 2-10 wk when similar samples were collected. RSV infection was documented first by identification of viral antigen in nasopharyngeal epithelial cells 
contained in the NPS specimens via indirect immunofluorescence, and subsequently confirmed by recovery of virus in tissue culture (4).

Determination of $R S V$ antibody titer. Titers of RSV-specific antibody were determined both in serum and in NPS using an ELISA described in detail in a previous publication from this laboratory (3). In brief, a stock strain of RSV was grown in tissue culture and purified on sucrose gradients. Aliquots of RSV or a control preparation of similarly processed tissue culture cells were allowed to adhere to wells in polyvinyl microtiter plates (Dynatech Laboratories, Alexandria, VA) and were inoculated with serial 2-fold dilutions of serum or NPS in phosphatebuffered saline. Wells were then incubated with horseradish peroxidase-conjugated goat antihuman IgE (Miles Laboratories, Elkhardt, IN) followed by incubation with a colorless substrate, 5-amino-salicylic acid (Sigma Chemicals, St. Louis, MO), which is converted to a purple-brown color by the action of peroxidase. End-points were read as the highest specimen dilution giving an absorbance value, read by colorimeter, greater than two times that of the control. The specificity of this assay for the IgE isotype was confirmed by blocking experiments in which positive reactions could be blocked by preincubation of the goat antihuman IgE with purified human IgE (Kallestad Laboratories, Chaska, MN) but not by preincubation with purified preparations of human IgG, IgM, IgA, or human immunoglobulin light chains. The specificity of the IgE detected for RSV was confirmed by experiments in which positive reactions could be blocked by preincubation of specimens of serum or NPS with RSV-infected tissue culture cells followed by centrifugation, but not by preincubation with uninfected tissue culture cells. Additional controls consisted of testing of known positive specimens with substrate but without conjugate, testing of virus-coated wells with conjugate and substrate but with buffer substituted for serum or secretions, and testing of the uninfected cell preparations mentioned above. All control testing yielded negative results. Finally samples of serum and secretions from patients with infection due to parainfluenza virus but without documented RSV infection gave negative results when tested with the current assay.

In the present study, samples of serum were diluted 1:4 before testing for RSV antibody. Samples of NPS, collected in polyethylene catheters, were rinsed into mucus traps using $0.5 \mathrm{ml}$ of phosphate-buffered saline before testing in the ELISA assay. The final volume of NPS and buffer ranged between 0.6 and $1.0 \mathrm{ml}$, so that samples of NPS were diluted a minimum of $50 \%$ in the collecting process. These samples were further diluted 1:4 before testing in the ELISA system. Therefore NPS specimens were tested at an actual dilution greater than that of serum specimens. Protein concentrations of NPS specimens were measured as a check on the degree of dilution.

Titers of RSV-specific IgE were measured in all samples of NPS and serum collected both at the time of acute illness and at the follow-up visit. Samples of both NPS and serum from 20 of these patients returning for follow-up were processed for determination additionally of RSV-IgG and RSV-IgA antibody titer using a similar ELISA system specific for $\operatorname{IgG}$ or $\operatorname{IgA}$ antibody. These 20 specimens were used to demonstrate the predominantly mucosal nature of the $\operatorname{IgE}$ and $\operatorname{IgA}$ antibody responses.

Statistical methods. All means of antibody titers measured were expressed as the geometric mean after base 10 logarithmic transformation of titers. Titers of $<4$ were assigned a value of 1 before logarithmic transformation. SDs were expressed as those calculated after logarithmic transformation of data. Comparisons of antibody responses and ratios of antibody were evaluated for statistical significance using Student's $t$ test. The frequencies of occurrence of RSV antibody in serum and NPS were compared by $\chi^{2}$ analysis with Yates' correction.

\section{RESULTS}

Kinetics of appearance of RSV-IgE in serum and secretions. The kinetics of appearance of RSV-IgE in samples of NPS and serum obtained simultaneously from patients with RSV infection at various intervals after the onset of illness is demonstrated in Figure 1. Results for individual patients are expressed only once each in the intervals from $1-14$ and 15-75 days after the onset of illness. At 1-5 days after the onset of illness, nine of $18(50 \%)$ patients already manifested RSV-IgE in NPS, with a GMT \pm SD of $2.4 \pm 1.3$. Simultaneously only three of $18(17 \%)$ patients exhibited RSV-IgE in serum $(\mathrm{GMT}=1.4 \pm 1.2)$. Similarly at 6 14 days after the onset of illness, 14 of $23(61 \%)$ patients tested had detectable RSV-IgE present in NPS (GMT $=2.8 \pm 1.3$ ), while only five of $23(22 \%)$ patients had detectable RSV-IgE in serum $(\mathrm{GMT}=1.3 \pm 1.2)$. At each interval, the difference in titer of RSV-IgE in NPS was statistically significantly greater than that in the serum (for each comparison, $p<0.02$ ). RSVIgE antibody was similarly found more frequently and in significantly higher titers in NPS than in serum when antibody responses at 15-45 and 46-75 days after the onset of illness were studied. The observed RSV-IgE titer in secretions at 46-75 days after the onset of illness may be artificially high due to the small sample size.

For all intervals studied, the difference in RSV-IgE titer between NPS and serum was particularly noteworthy because of the comparatively increased dilution of NPS specimens as a result of the collection process (see "Materials and Methods").

Frequency of isolated appearance of $R S V-\operatorname{IgE}$ at each sample site. In identifying formation of IgE as a mucosal process, it is important to note the frequency with which RSV-IgE was present only at one of the sample sites, and not at the other. Such an analysis is shown in Table 1. Again the increased dilution of NPS specimens would favor an increased frequency of patients with positive tests for RSV-IgE in serum with negative results in NPS. Despite this tendency, it was more common to find RSVIgE in NPS but not in serum than the converse. For example, in the first 14 days after the onset of illness 19 of $41(46 \%)$ of patients studied had detectable RSV-IgE in NPS but not in serum, while only four of $41(10 \%)$ had RSV-IgE detectable in serum but not NPS $(p<0.01)$. Four patients $(10 \%)$ had RSVIgE detectable at both sample sites, while $14(34 \%)$ patients were negative for RSV-IgE at both sites. Similar results were obtained

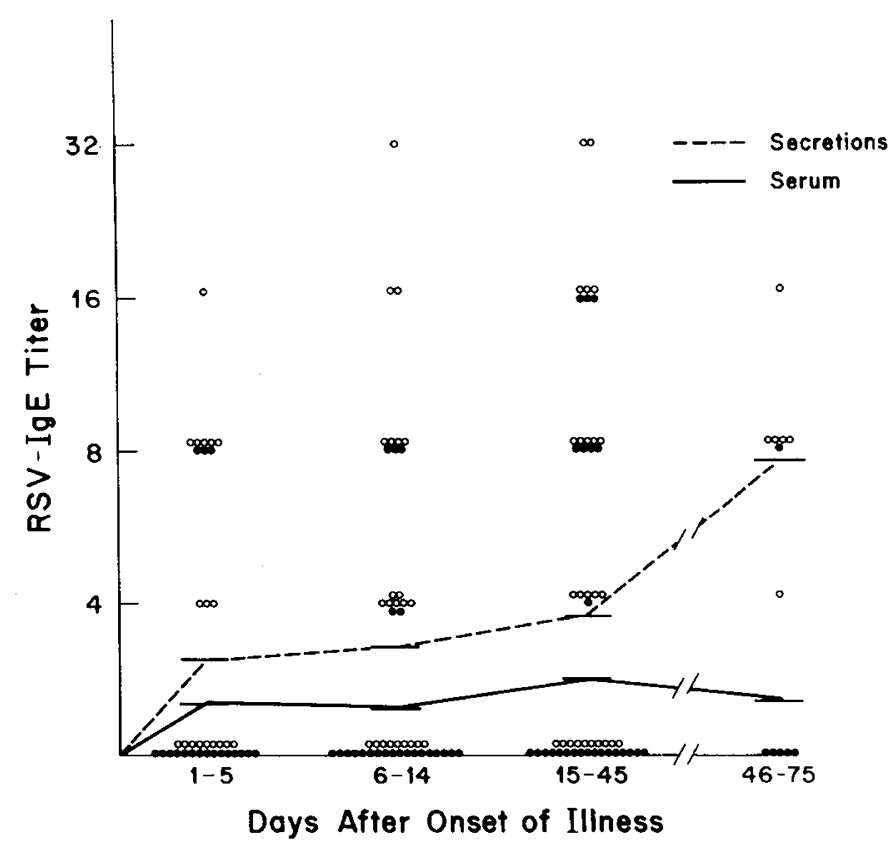

Fig. 1. Kinetics of appearance of RSV-specific IgE antibody in simultaneously obtained samples of nasopharyngeal secretions (open circles) and serum (closed circles) at various intervals after the onset of illness. Broken line connects geometric mean titers of RSV-IgE in secretions; solid line connects geometric mean titers of RSV-IgE in serum. 
Table 1. A comparison of the occurrence of RSV-IgE responses in simultaneously-obtained specimens of serum and NPS

\begin{tabular}{|c|c|c|c|c|c|}
\hline \multirow[b]{2}{*}{$\begin{array}{l}\text { Days after } \\
\text { onset of } \\
\text { illness }\end{array}$} & \multirow[b]{2}{*}{$\begin{array}{l}\text { No. } \\
\text { tested }\end{array}$} & \multirow{2}{*}{$\begin{array}{l}\text { Both NPS } \\
\text { positive* } \\
\text { and serum } \\
\text { positive }\end{array}$} & \multicolumn{3}{|c|}{ Presence of RSV-IgE in specimen } \\
\hline & & & $\begin{array}{l}\text { NPS positive } \\
\text { with serum } \\
\text { negative }\end{array}$ & $\begin{array}{l}\text { NPS negative } \\
\text { with serum } \\
\text { positive }\end{array}$ & $\begin{array}{c}\text { NPS negative } \\
\text { and serum } \\
\text { negative }\end{array}$ \\
\hline $1-14$ & 41 & 4 & $19 \dagger$ & $4 \dagger$ & 14 \\
\hline $15-75$ & 31 & 7 & $14 \ddagger$ & $2 \ddagger$ & 8 \\
\hline
\end{tabular}

\footnotetext{
* NPS specimens diluted at least $1: 1$ during collection.

$\dagger \ddagger$ Frequency of NPS-positive, serum-negative specimens exceeds that of NPS-negative, serum-positive specimens (for each comparison, $p<$ $0.01)$.
}

Table 2. Simultaneous serum and NPS ELISA titers of RSV antibody in 20 selected subjects

\begin{tabular}{|c|c|c|c|c|c|}
\hline \multirow[b]{2}{*}{ Sample source } & \multicolumn{3}{|c|}{$\begin{array}{l}\text { RSV-specific antibody titer (geometric mean } \pm \\
\text { SE) }\end{array}$} & \multicolumn{2}{|c|}{$\begin{array}{l}\text { RSV-antibody isotype ratios (geo- } \\
\text { metric mean } \pm \mathrm{SE} \text { ) }\end{array}$} \\
\hline & $\mathrm{IgG}$ & $\operatorname{Ig} \mathrm{A}$ & IgE & IgA/IgG & IgE/IgG \\
\hline Serum & $302 \pm 0.3$ & $3.3 \pm 0.4$ & $2.6 \pm 0.2$ & $0.09 \pm 1.0 \dagger$ & $0.05 \pm 0.22 \ddagger$ \\
\hline Ratio (NPS/serum) & 0.01 & 2.42 & 2.00 & & \\
\hline
\end{tabular}

* Samples diluted at least $1: 1$ during collection.

$\dagger p<0.001$.

$\ddagger p<0.001$.

when patients were tested in follow-up at 15-75 days after the onset of illness. At this interval 14 of 31 (45\%) patients had RSVIgE in NPS but not in serum, while only two of $31(6 \%)$ patients had RSV-IgE in serum but not NPS $(p<0.01)$. Seven patients (23\%) were positive at both sites, while eight patients $(26 \%)$ were negative at both sites. In all cases in which RSV-IgE was detectable in serum but not in NPS, the protein content of NPS specimens in buffer was $\leq 0.1 \mathrm{mg}$ protein per milliliter of fluid, whereas protein concentrations in other NPS samples were usually $1.0 \mathrm{mg}$ protein per milliliter of fluid or more. These findings suggest that negative assays for RSV-IgE in NPS specimens from these patients may have been due to a small volume of NPS having been collected initially.

Comparison of RSV-IgE levels to that of other isotypes in NPS and serum. A comparison of titers of RSV-IgE antibody in serum and NPS to those of RSV-IgA and RSV-IgG antibody in the same fluids was carried out in 20 patients, each of whom had samples of NPS and serum obtained for this purpose at the follow-up visit. Aliquots of each sample were tested for the presence of RSV antibody in each isotype class using an identical ELISA assay. RSV-IgA was, as expected, the predominant antibody isotype in NPS (Table 2), the titers of RSV-IgE and RSV$\mathrm{IgG}$ did not differ from each other statistically $(p>0.10)$. RSVIgG was, by far, the predominant antibody isotype found in serum. Ratios of the group geometric mean antibody titer for each isotype in NPS to that in serum were 0.01 for RSV-IgG, 2.42 for RSV-IgA, and 2.00 for RSV-IgE, strongly suggesting a predominantly mucosal response for both RSV-IgA and RSV$\mathrm{IgE}$, but not for RSV-IgG. Furthermore the geometric mean $( \pm$ $\mathrm{SE}$ ) value of the 20 individual $\mathrm{RSV}-\mathrm{Ig} \mathrm{A} / \mathrm{RSV}$-IgG titer ratios in NPS $(1.85 \pm 0.44)$ was significantly greater than the corresponding value for serum samples $(0.09 \pm 1.0, p<0.001)$, and the geometric mean value of the 20 individual RSV-IgE/RSV-IgG ratios in NPS $(1.74 \pm 0.28)$ was significantly greater than the corresponding value in serum $(0.05 \pm 0.22, p<0.001)$.

Analysis of RSV-IgE responses in serum by illness group. RSVIgE responses in serum are analyzed by the form of patient illness in Table 3. In patients with URI alone, RSV-IgE was not observed in serum specimens obtained from eight patients from 114 days after the onset of illness, or from three patients studied 15-45 days after the onset of illness. During the interval from 46-75 days after the onset of illness, two of six (33\%) patients had detectable RSV-IgE in serum (GMT $\pm \mathrm{SD}=1.6 \pm 1.9)$.
Similarly the small number of patients with pneumonia studied from 1-45 days after the onset of illness did not manifest detectable serum RSV-IgE. In contrast eight of $27(30 \%)$ patients with bronchiolitis had RSV-IgE detected in serum specimens obtained 1-14 days after the onset of illness (GMT $=1.6 \pm 2.1$ ), two of eight $(25 \%)$ patients had detectable serum RSV-IgE when studied at $15-45$ days after the onset of illness (GMT $=2.2 \pm$ 4.3), and five of $12(42 \%)$ patients had detectable serum RSVIgE when studied 46-75 days after the onset of illness (GMT = $2.1 \pm 2.7)$. The differences in titer of RSV-IgE between the bronchiolitis group and either the URI group alone or the combined URI and pneumonia (nonwheezing) groups were statistically significant $(p<0.001)$ at the interval $1-14$ days after the onset of illness. Differences in titer of RSV-IgE among the same groups at the other intervals shown in Table 3 were not statistically significant.

An analysis of the relationship of RSV-IgE responses in NPS to the form of illness due to RSV infection in other infants similar to these has been previously published (3).

\section{DISCUSSION}

IgE-bearing plasmacytes have been reported to be present in either respiratory tract mucosa or its lymphoid tissue (5-9). The validity of some of these studies has been challenged in that IgE may have been bound to the surface of plasmacytes by $\mathrm{Fc}$ receptors, rather than being present as a result of active synthesis (10). IgE visualized by indirect immunofluorescence techniques might also have been present solely as a result of binding to mucosal mast cells (11). Other investigators, using similar techniques, have not been able to confirm the presence of IgE-bearing plasmacytes in respiratory tract tissues (12-14). Even if IgEforming plasmacytes are present in the respiratory tract, this does not establish IgE as a predominantly mucosal immunoglobulin unless it can be shown that the relative proportion of IgEproducing cells among plasmacytes producing other immunoglobulin isotypes is increased in mucosal sites in comparison to peripheral blood or systemic lymphoid tissue (5). Even then, it is not clear that actual production of IgE (in contrast to simple presence of capable cells) is increased in the mucosa. Ohta et al. (15) demonstrated that irradiated tonsillar lymphocytes were capable of IgE synthesis in vitro, but direct comparisons to IgE 
Table 3. Serum RSV-specific IgE responses analyzed by form of illness

RSV-IgE response (no. positive $\div$ number tested; GMT $\pm \mathrm{SD}$ ) (days after onset of illness)

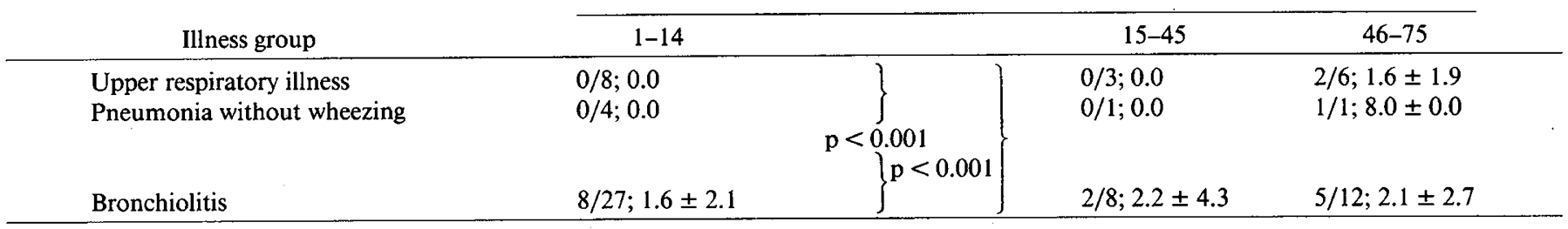

synthesis by peripheral blood cells were not made. Taking another approach Deuschl and Johansson (1) demonstrated that ratios of total IgE to albumin were greater in bronchial secretions than in serum. Platts-Mills (2) demonstrated evidence of local IgG production in the respiratory tract and concluded, since quantities of rye I antigen-specific IgE in nasal secretions correlated with the amount of $\operatorname{IgG}$ antibody, that $\operatorname{IgE}$ was also locally produced. The present study of IgE antibody responses to an infectious agent is of interest in that it permits direct measurement of IgE responses simultaneously in serum and respiratory secretions following a single, known exposure to the antigen. The data presented strongly support the concept of RSV-IgE production as being predominantly a mucosal process in that RSV-IgE was frequently present in respiratory secretions while absent in serum, in that titers of RSV-IgE were greater in secretions than in simultaneously obtained serum samples, and in that mean ratios of peak RSV-IgE/RSV-IgG responses were significantly greater in secretions than in serum.

This study did not attempt to address the question of whether or not IgE is a secretory antibody. Secretory IgA differs from serum IgA in molecular weight (essentially due to the dimeric nature of the secretory immunoglobulin) as well as the presence of secretory component and the joining chain (16). None of these differences between immunoglobulin found in serum and in secretions has been identified for $\operatorname{IgE}(16,17)$, so there is little reason currently to think of $\mathrm{IgE}$ as a secretory immunoglobulin (18). The present study contains no data to support or refute the possibility that some of the RSV-IgE detected in NPS might have been present as a result of release from mucosal mast cell membranes.

The finding in the present study that titers of RSV-IgE in NPS were nearly equivalent to titers of RSV-IgG in secretions might be surprising to some, in that previous studies of rye I antigenspecific antibody in nasal secretions (2) or total immunoglobulin concentrations in secretions (15) demonstrated that $\operatorname{IgG}$ and IgA were present in greater concentrations than $\mathrm{IgE}$. In both of these studies, the concentrations of $\operatorname{IgE}$, but not $\operatorname{IgG}$ or $\operatorname{IgA}$, were greater in allergic individuals than in normal controls. The present study determined RSV-IgE responses primarily in patients with bronchiolitis, who are known to have hyperresponsiveness in terms of virus specific IgE production both in serum (Table 3) and secretions (3) in comparison to patients with RSV infection who do not develop bronchiolitis. In general, then, we expect that quantities of RSV-IgE in secretions of most individuals, including those who experience RSV infection without wheezing, may be less than quantities of RSV-IgG.

Since RSV infection is generally considered a mucosal illness with no viremic phase (19) one might expect the RSV-IgE antibody response to occur predominantly at the mucosal surface also. Nevertheless a previous study from this laboratory demonstrated that RSV infection results in RSV-IgG and RVS-IgM antibody response in serum (20) which are in excess of those in respiratory secretions (21), while the RSV-IgA response occurs predominantly in secretions. Therefore the predominance of the RSV-IgE response in secretions seen in the current study cannot be explained simply by the restriction of the infectious agent to the respiratory mucosa. Also, since RSV-specific IgG, IgM, and
IgA antibodies appear in both serum and secretions simultaneously with RSV-IgE, the observed differences in measured titers of RSV-IgE between serum and secretions cannot be explained simply as a function of the presence of blocking antibody of other isotypes in one body fluid but not the other.

Identification of the mucosa as the principal site of IgE production is potentially of great interest. There is good evidence for the existence of a common mucosal immune system (22) such that induction of an IgA response at one mucosal surface results in the appearance of IgA at all mucosal surfaces. Therefore it would be expected that induction of an antigen-specific IgE response at one mucosal surface might also result in the appearance of IgE at distant mucosal sites, thereby sensitizing the host to antigenic exposure subsequently at the distant mucosal sites. Also, substances capable of selectively suppressing IgE production have been identified $(23,24)$. If $\operatorname{IgE}$ synthesis is truly a mucosal phenomenon, local application of suppressor substances might be expected to be both more effective and less toxic in suppressing IgE responses in the host.

Acknowledgments. The authors thank Kathy Shero for assistance in manuscript preparation.

\section{REFERENCES}

1. Deuschl H, Johansson SJO 1974 Immunoglobulin in tracheobronchial secretion with special reference to IgE. Clin Exp Immunol 16:401-412

2. Platts-Mills TAE 1979 Local production of $\operatorname{IgG}, \operatorname{IgA}$, and $\operatorname{IgE}$ antibodies in grass pollen hay fever. J Immunol 122:2218-2225

3. Welliver RC, Wong DT, Sun M, Middleton E, Vaughan RS, Ogra PL 1981 The development of respiratory syncytial virus-specific IgE and the release of histamine in nasopharyngeal secretions after infection. $N$ Engl $J$ Med 305:841-846

4. Kaul A, Scott R, Gallagher M, Scott M, Clement J, Ogra PL 1978 Respiratory syncytial virus infection. Am J Dis Child 132:1088-1090

5. Tada T, Ishizaka K 1970 Distribution of $\gamma \mathrm{E}$-forming cells on lymphoid tissue of the human and monkey. J Immunol 104:377-387

6. Ostergaard PA 1982 Tonsillar IgE plasma cells predict atopic disease. Clin Exp Immunol 49:163-166

7. Brochier J, Samarut C, Bich-Thuy LT, Revillard JP 1978 Study of human T and B lymphocytes with heterologous antisera. IV. Subpopulation in tonsil and adenoid cell suspension. Immunology 35:827-835

8. Callerame ML, Condemi JJ, Ishizaka K, Johansson SGO, Vaughan JH 1971 Immunoglobulins in bronchial tissues from patients with asthma with special reference to immunoglobulin E. J Allergy 47:187-197

9. Lawrence EC, Blaese RM, Martin RR, Stevens PM 1978 Immunoglobulin secreting cells in normal human bronchial lavage fluid. I Clin Invest 62:832835

10. Brandtzaeg $P$, Baklien K 1976 Inconclusive immunohistochemistry of human IgE in mucosal pathology. Lancet 1:1297-1298

11. Mayrohofer C Bazin H, Gowans JL 1976 Nature of cell binding anti-IgE in rats immunized with Nippostrongylus Brasiliensis: IgE synthesis in regional nodes and concentrations in mucosal mast cells. Eur J Immunol 6:537-548

12. Brandtzaeg $P$, Surjan L, Berdal $P 1978$ Immunoglobulin systems of human tonsils. I. Control subjects of various ages: quantification of Ig-production cells, tonsillar morphometry and serum Ig concentrations. Clin Exp Immunol 31:367-381

13. Surjan L, Brandtzaeg $P$, Berdal $P 1978$ Immunoglobulin systems of human tonsils. II. Patients with chronic tonsillitis or tonsillar hyperplasia: Quantification of Ig-producing cells, tonsillar morphometry and serum Ig concentrations. Clin Exp Immunol 31:382-390

14. Korsrud FR, Brandtzaeg P 1980 Immune systems of human nasopharyngeal and palatine tonsils: histomorphometry of lymphoid components and quantification of immunoglobulin-producing cells in health and disease. Clin Exp Immunol 39:361-370

15. Ohta K, Manzara T, Harbeck RJ, Kirkpatrick CH 1983 Human tonsillar IgE 
biosynthesis in vitro. I. Enhancement of IgE and IgG synthesis in the presence of pokeweed mitogen by T-cell irradiation. J Allergy Clin Immunol 71:212223

16. Tomasi TB Jr 1982 Secretory immunoglobulins. N Engl J Med 287:500-506

17. Newcomb R, Ishizaka K 1970 Physiochemical and antigenic studies on human IgE in respiratory fluids. J Immunol 105:85-89

18. Nakajima S, Gillespie DN, Gleich GJ 1975 Differences between IgA and IgE as secretory proteins. Clin Exp Immunol 21:306-317

19. Chanock RM, Kim HW, Brandt CD, Parrott RH 1982 Respiratory syncytial virus. In: Evans AS (ed) Viral Infections of Humans: Epidemiology and Control. Plenum Medical Book Company, New York, pp 471-488

20. Welliver RC, Kaul TN, Putnam TI, Sun M, Riddlesberger K, Ogra PL 1980 The antibody response to primary and secondary infection with respiratory syncytial virus: kinetics of class-specific responses. J Pediatr 96:808-813
21. Kaul TN, Welliver RC, Wong DT, Udwadia RA, Riddlesberger K, Ogra PL 1981 Secretory antibody response to respiratory syncytial virus infection. Am J Dis Child 135:1013-1016

22. McDermott MR, Bienenstock T 1979 Evidence for a common mucosal immunologic system. I. Migration of B immunoblasts into intestinal, respiratory, and genital tissues. J Immunol 122:1892-1898

23. Katz DH, Bargatze RF, Bogowitz CA, Matz LR 1980 Regulation of IgE antibody production by serum molecules. VII. The IgE-selective damping activity of suppressive factor of allergy (SFA) is exerted across both strain and species restriction barriers. J Immunol 124:819-824

24. Zuraw BL, Noaka M, O'Hair C, Katz DH 1981 Human IgE antibody synthesis in vitro: stimulation of $\mathrm{IgE}$ response by pokeweed mitogen and selective inhibition of such responses by human suppressive factor of allergy (SFA). $\mathfrak{J}$ Immunol 127:1169-1174

\title{
Hypouricemia in Neonates with Syndrome of Inappropriate Secretion of Antidiuretic Hormone
}

\author{
FARAHNAK K. ASSADI AND EUNICE G. JOHN \\ Department of Pediatrics, University of Illinois Health Sciences Center, Chicago, Illinois 60612
}

\begin{abstract}
A prospective study of serum levels of uric acid in 23 hyponatremic neonates was performed. Infants on diuretic medications or with renal failure were excluded. The infants were separated into two groups: group I consisted of 11 neonates with clinical evidence of syndrome of inappropriate secretion of antidiuretic hormone (SIADH), (mean $\pm \mathrm{SD}$ serum sodium $127 \pm 1.36 \mathrm{mEq} /$ liter). Group II included 12 infants with hyponatremia (mean serum sodium $128 \pm 1.10 \mathrm{mEq} /$ liter) associated with decreased effective vascular volume manifest by a fractional sodium excretion $<1 \%$. The groups were similar for gestational and postnatal ages, birth weight, clinical conditions, and concurrent use of drugs. The serum urate concentation in neonates with SIADH was $2.46 \pm 0.54 \mathrm{mg} / \mathrm{dl}$; serum urate concentration in group II infants was $8.49 \pm 2.45 \mathrm{mg} / \mathrm{dL}$ $(p<0.001)$. Water restriction in the group I infants with SIADH resulted in a rise in mean serum urate concentration $(p<0.001)$. Fractional excretion of urate was elevated during hyponatremia in the group I infants (to $78 \pm 0.13 \%$ ) and fell to $51 \pm 0.08 \%$ after correction $(p<0.001)$. In group I infants, a direct correlation was found between fractional excretion of urate and sodium $(r=0.7667, p<$ 0.001 ). These results indicate that hypouricemia is common in infants with suspected SIADH and seems to be due to increased urate clearance secondary to volume expansion. (Pediatr Res 19: 424-427, 1985)
\end{abstract}

\section{Abbreviations}

SIADH, syndrome of inappropriate secretion of antidiuretic hormone

$\mathrm{FE}_{\mathrm{Na}}$, fractional sodium excretion

SUr, serum urate concentration

Received September 27, 1984; accepted December 21, 1984.

Reprint requests Dr. Farahnak K. Assadi, Department of Pediatrics, University of Illinois Health Sciences Center, 840 South Wood Street, Chicago, IL 60612.

\author{
$\mathrm{FE}_{\mathrm{Ur}}$, fractional urate excretion \\ ECFV, extracellular fluid volume \\ AVP, arginine vasopressin \\ $\mathrm{C}_{\mathrm{Cr}}$, creatinine clearance
}

The diagnosis of SIADH in neonates and its differentiation from other common causes of hyponatremia is often difficult (1-6). In the syndrome of SIADH, dilution of body fluids occurs because of the inability of the kidney to excrete free water appropriately. Total body sodium content is normal or only moderately decreased; intravascular volume is slightly increased $(7,8)$. In most other hyponatremic syndromes there is either a marked increase (as in edematous states) or a marked decrease in total body sodium (as in true hypovolemia). In these latter conditions, excretion of water by the kidney may be impaired as a result of the decrease in effective intravascular volume (9). This in turn may cause decreased delivery of glomerular filtrate to distal nephron sites of dilution (10) or may initiate a nonosmolar stimulus to pituitary antidiuretic hormone release (9).

The present study was conducted to test the hypothesis that the "effective intravascular volume" is a potent modulator of renal urate clearance by the kidney and that SUr might reflect changes in effective volume (11-13).

\section{PATENTS AND METHODS}

Twenty-three newborn infants with postnatal ages ranging from 2 to 7 days were evaluated because of hyponatremia (serum sodium concentration $<130 \mathrm{mEq} /$ liter) and hypoosmolality of body fluids (serum osmolality $<270 \mathrm{mOsmol} / \mathrm{kg}$ ) of 1 to 3 days duration. Patients with evidence of renal insufficiency (abnormal urinary sediment, serum concentration of creatinine of greater than $1 \mathrm{mg} / \mathrm{dl}$ ) were excluded from study. Also excluded were 